University of Nebraska - Lincoln

DigitalCommons@University of Nebraska - Lincoln

Nebraska Cooperative Fish \& Wildlife Research Nebraska Cooperative Fish \& Wildlife Research Unit -- Staff Publications

2011

\title{
Pathology and failure in the design and implementation of adaptive management
}

Craig R. Allen

University of Nebraska-Lincoln, callen3@unl.edu

Lance H. Gunderson

Emory University, Igunder@emory.edu

Follow this and additional works at: https://digitalcommons.unl.edu/ncfwrustaff

Part of the Other Environmental Sciences Commons

Allen, Craig R. and Gunderson, Lance H., "Pathology and failure in the design and implementation of adaptive management" (2011). Nebraska Cooperative Fish \& Wildlife Research Unit -- Staff Publications. 79.

https://digitalcommons.unl.edu/ncfwrustaff/79

This Article is brought to you for free and open access by the Nebraska Cooperative Fish \& Wildlife Research Unit at DigitalCommons@University of Nebraska - Lincoln. It has been accepted for inclusion in Nebraska Cooperative Fish \& Wildlife Research Unit -- Staff Publications by an authorized administrator of DigitalCommons@University of Nebraska - Lincoln. 


\title{
Pathology and failure in the design and implementation of adaptive management
}

\author{
Craig R. Allen ${ }^{\mathrm{a}, *}$, Lance H. Gunderson ${ }^{\mathrm{b}}$ \\ ${ }^{a}$ U.S. Geological Survey, Nebraska Cooperative Fish and Wildife Research Unit, School of Natural Resources, University of Nebraska, Lincoln, NE, USA \\ ${ }^{\mathrm{b}}$ Department of Environmental Studies, Emory University, Atlanta, GA, USA
}

\section{A R T I C L E I N F O}

Article history:

Received 12 October 2010

Accepted 29 October 2010

Available online 26 November 2010

\section{Keywords:}

Inference

Management

Resilience

Resource management

Risk

Uncertainty

\begin{abstract}
A B S T R A C T
The conceptual underpinnings for adaptive management are simple; there will always be inherent uncertainty and unpredictability in the dynamics and behavior of complex ecological systems as a result non-linear interactions among components and emergence, yet management decisions must still be made. The strength of adaptive management is in the recognition and confrontation of such uncertainty. Rather than ignore uncertainty, or use it to preclude management actions, adaptive management can foster resilience and flexibility to cope with an uncertain future, and develop safe to fail management approaches that acknowledge inevitable changes and surprises. Since its initial introduction, adaptive management has been hailed as a solution to endless trial and error approaches to complex natural resource management challenges. However, its implementation has failed more often than not. It does not produce easy answers, and it is appropriate in only a subset of natural resource management problems. Clearly adaptive management has great potential when applied appropriately. Just as clearly adaptive management has seemingly failed to live up to its high expectations. Why? We outline nine pathologies and challenges that can lead to failure in adaptive management programs. We focus on general sources of failures in adaptive management, so that others can avoid these pitfalls in the future. Adaptive management can be a powerful and beneficial tool when applied correctly to appropriate management problems; the challenge is to keep the concept of adaptive management from being hijacked for inappropriate use.
\end{abstract}

Published by Elsevier Ltd.

\section{Introduction}

Adaptive management is natural resource management conducted in a manner that purposely and explicitly increases knowledge (enhances learning) and decreases uncertainty (Holling, 1978; Walters, 1986; Williams et al., 2009) while allowing management to proceed despite the uncertainty present. Adaptive management uses management actions as experiments to provide data supporting, or failing to support, competing hypotheses when there is uncertainty regarding the response of ecological systems to management activities, to better meet management objectives over time. Adaptive management is a form of structured decision making, and structured decision making and adaptive management are often used synonymously in natural resource management. Adaptive management as originally envisioned by Holling (1978) and Walters (1986) is now more precisely termed active adaptive management. The differences between structured

\footnotetext{
* Corresponding author.

E-mail address: allencr@unl.edu (C.R. Allen).
}

decision making, passive adaptive management and active adaptive management are discussed elsewhere in this volume of the Journal of Environmental Management. Additionally, natural resource decision making is conducted within the constraints of broader social and political systems, which often confine or constrain the ability to manage adaptively (or to manage at all, in some cases). As a result, some authors define adaptive governance (sensu Gunderson and Light, 2006) as the institutional framework that deals with social and political dimensions of resource management and that allows adaptive management to function. Policy may directly influence management or may instead provide incentives or disincentives to encourage desired outcomes.

Here we focus on what is now commonly referred to as active adaptive management (Walters, 1986); however, the pathologies we identify may be present in other forms of adaptive management, or in any type of resource management, for that matter. Similarly, the solutions are similar. Active adaptive management is appropriately utilized when a natural resource is clearly in need of some management action (i.e., in a perceived less than desirable state), management actions are logistically, financially and politically feasible, but the response of the resource to a particular management action is 
uncertain. Furthermore, because of different viewpoints, or biases, coupled with uncertainty, different stakeholders or managers or scientists may have different ideas regarding how a system is likely to respond to management, and underlying this are diverse hypotheses of cause and effect. Those competing hypotheses are then put at risk by applying management experimentally. As an example, consider a rare and declining species such as the least tern (Sternula antillarum). There are several potential reasons why this species is declining; most (but not all) managers accept that the decline is related to a reduction in available habitat. But, habitat is a vague concept and there is uncertainty regarding what habitat element has been reduced for terns, and how that might be recovered by potential management actions. It may be that woody or herbaceous vegetation is encroaching on tern habitat, it may be that some change in habitat conditions increased populations of nest predators, or that foraging habitat has declined, resulting in reduced survival of young. More hypotheses are possible as well. An adaptive management approach may first design concurrent replicated manipulations of vegetation and predator populations to determine which, if any, produces a positive response in tern populations. If habitat improvement by reducing herbaceous vegetation produces a positive response, there is still uncertainty in how to best achieve the manipulation of herbaceous vegetation while promoting a positive response in tern populations. Is it best achieved by herbicide application or by physically manipulating the environment with bulldozers? Or, is it best achieved by restoring spring pulse flows of rivers? A seemingly simple natural resource management problem how can we increase populations of terns - can be very complex (and this is without considering the socio-political aspects of species and habitat management). And in this example, questions of food availability for tern chicks have not been addressed. Nor have questions of interactions and multi-causality or non-linearity, which are common in ecological systems. This example also illustrates the need for monitoring (of, for example, least tern reproduction, vegetation dynamics, and forage fish populations), and an iterative approach to management experiments designed to test the hypotheses of effect forwarded by managers and stakeholders. Such an approach is not trial and error, nor haphazard sequences of different management options.

Since its initial introduction and description, adaptive management has been hailed as a solution to endless trial and error approaches to complex natural resource management challenges. However, its implementation has failed more often than not. It does not produce easy answers, and it is appropriate in only a subset of natural resource management problems. It is not a panacea for the navigation of 'wicked problems' (Rittel and Webber, 1973; Ludwig, 2001). Adaptive management is not possible, or needed, in most situations (Gregory et al., 2006). Adaptive management and related approaches are appropriate where both uncertainty and controllability are high (Fig. 1). If uncertainty is high but controllability is low, scenarios are a more appropriate approach and allow for the exploration of potential future outcomes of present actions (Baron et al., 2009). Adaptive management is a poor fit for solving problems of intricate complexity, high external influences, long time spans, high structural uncertainty and with low confidence in assessments (Gregory et al., 2006)(e.g., climate change). However, even in such situations, adaptive management may be the preferred alternative, and can be utilized to resolve or reduce structural uncertainty, for example.

The implementation of adaptive management has proven to be difficult. Despite attempts to integrate adaptive management into land management in the United States (e.g., Williams et al., 2009), Australia, and elsewhere, these programs are often adaptive management programs in name only and never reach fruition or meet expectation (Allan and Curtis, 2005). The reasons for failure

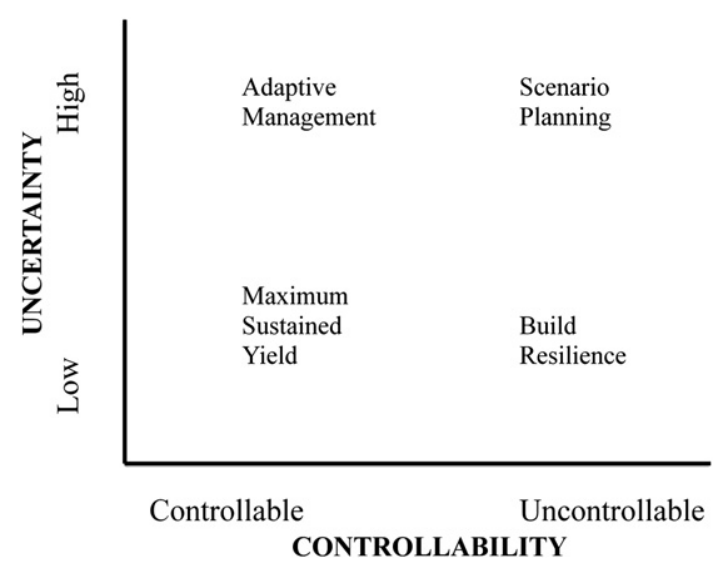

Fig. 1. Adaptive management and scenarios are complementary approaches to understanding complex systems. Adaptive management functions best when both uncertainty and controllability are high, which means the potential for learning is high, and the system can be manipulated (adapted from Peterson et al., 2003).

as assessed by others include: 1 ), the failure of scientists to understand the array of management possible or to recognize the need to provide information that can be directly used by decision makers (Gregory et al., 2006); 2), the failure of decision makers to understand why adaptive management is needed (Walters, 2007); 3), the failure by overlapping management agencies to clearly define their responsibilities for implementing an adaptive management plan (Gregory et al., 2006); 4), an agency belief that single best policies lend credibility (Walters, 1997); 5), a lack of leadership for the complex process of implementing an adaptive approach (Walters, 2007); 6), the hijacking of management goals for research interests (Walters, 1997); 7), using bureaucratic and political inaction as a policy choice (Walters, 1997); 8), a lack of emphasis or attention to the processes required for building shared understanding and shared decision making among diverse stakeholders (Gregory et al., 2006); 9), the tendency among scientists to overstate their capability to measure complex functional relationships through experimentation (Gregory et al., 2006; p. 2413); 10), valuing action more than learning (Lee, 1999); 11), difficulties in translating learning into practice (Lee, 1999); 12), the cost and delays associated with gathering information and learning (Lee, 1999); 13), uncertainty in whether the adaptive management approach works (Lee, 1999); and 14), inadequate funding for the increased monitoring needed to successfully compare the outcomes of alternative policies (Walters, 2007). Adaptive management experiments that entail long time frames and large areas have not been carried out in many systems because of high perceived costs (Walters, 1997; Moir and Block, 2001). Other programmatic failures can be attributed to the unwillingness of managers to risk experimentation with rare or vulnerable resources (Feldman, 2008).

Clearly adaptive management has great potential when applied to appropriate problems. Just as clearly adaptive management has frequently failed to live up to its high expectations. Why? Here we discuss nine pathologies and challenges that can lead to failure in adaptive management programs. These challenges exist in adaptive management programs in the United States and may be unique to that setting. The United States is characterized by large and powerful bureaucracies charged with natural resource management; stakeholders with different values and objectives, motivation and resources; a strong legal institution which has been the arena of resolution of many environmental issues; and a fragmentation of environmental research and practice in many areas. We focus on general sources of failures in adaptive management, 
so that others can avoid these pitfalls in the future. We believe that adaptive management can be a powerful and beneficial tool when applied correctly to appropriate problems. We have identified nine pathologies in the implementation of adaptive management, which represent broad and commonly repeated sources of failure; they are listed and discussed below.

\section{Pathologies in adaptive management}

\subsection{Lack of stakeholder engagement}

A lack of engagement of stakeholders early in the adaptive management process can lead to stakeholders rejecting results that vary from their expectations. Similarly, failure to include crucial stakeholders, because of accident or malice, can have similar results. Managers of natural resources are often dealing with management decisions that are contentious. Contention may arise from the rarity of a resource, or because different resource users have very disparate views on the best uses or management of a specific resource. Resource managers must make management decisions regardless of uncertainty and in the face of differing stakeholder values and objectives. Managers, however, often lack training in social sciences, including facilitation. Rather than engage stakeholders in complex and potentially protracted negotiation towards formalization of the disparate hypotheses of response to management underlying stakeholders differing worldviews, managers may attempt to anticipate users' viewpoints.

Government agencies often hold sway among stakeholders in complex regional scale adaptive management processes. They are often the legally empowered, technically astute and the primary funders of much of the adaptive management actions. Agency personnel are charged with designing research, monitoring and evaluation. A challenge in adaptive management is the recognition by key agency personnel that they will have to become engaged in activities that are outside their own agency mandate, and that they may have to agree to involvement from parties who are affected by their management decisions but have no legal authority. Bridging this legal gap is a challenge. The Federal Advisory Committee Act (FACA) is a statute that guides the way in which citizens and other entities can become engaged with agencies. How federal agencies choose to apply this law can be either a barrier or bridge to adaptive management. The Glen Canyon Adaptive Management Program is an example of such a FACA committee. When former Secretary of the Interior Bruce Babbitt established the program, he made sure the rules of FACA were followed to legitimize the group activity, even though its role is as an advisory group to the Secretary.

The process of stakeholder engagement is critically important for adaptive management. Adaptive management as originally envisioned (Holling, 1978; Walters, 1986) was developed to bridge interdisciplinary gaps among scientists and managers. That is, it involved the development of computer models as tools for translating scientific understanding and jargon into a common framework. The computer model as such was a tool for communicating among a smaller subset of technical specialists rather than a larger group of politically and socially engaged stakeholders. By the early 1990's some scholars (Lee, 1993; Gunderson et al., 1995) recognized that the social and political dimensions that accompany stakeholder involvement were different from the type of scientific community from which adaptive management arose. As a result, developments such as collaborative adaptive management emerged, which was developed to bring together the scientific strengths of adaptive management with the lessons from collaborative management. This blend was adopted in the formation of the adaptive management program in Glen Canyon in the late 1990's. The Glen Canyon program developed a series of protocols about how the group operates and used a facilitator to moderate the group meetings. Recent evaluations (Susskind et al., 2010) have suggested that for various reasons, the collaborative processes have either failed to change policies or to resolve unclear mandates. Failures in collaboration can limit and impede the ability to conduct adaptive management experiments, a barrier that has been recognized for a long time (Lee, 1993; Gunderson et al., 1995; Walters, 1986, 1997).

\subsection{Experiments are difficult}

Several of the more well-known examples of adaptive management in the United States have focused on systems that are extremely large, are slow to respond to any intervention, and occur at temporal and spatial scales where replication is not possible. This includes attempts to restore the Everglades in Florida, The Colorado River in the American Southwest, the Columbia River in the Pacific Northwest and the Platte River in Nebraska. In addition to problems inherent in managing systems at such large scales, the crossjurisdictional nature of such large ecological systems seems to yield governance structures that are similarly large and complicated. Such governance can fail, because it may be in a specific stakeholder's best interest to not undertake experimental actions that would help sort among alternative hypotheses of causation under consideration, or to misdirect attention from relevant hypotheses (e.g., sea lion predation of salmon at the mouth of the Columbia River as the primary hypothesis for salmon decline).

The reluctance to experiment can also be manifest as a need for control (Allan and Curtis, 2005) from a range of stakeholders including agencies. This need for control can be from governance committees, from agencies with the primary responsibility for management, or from other sources (Holling and Meffe, 1996). It is manifest in narrowly focused policies, lack of true stakeholder input, and overly complicated governance.

In addition to the type of institutional complexities and scales of controllability mentioned previously, there are other reasons that can preclude experimentation. An important factor is the cost of experimentation (Walters, 1997). Those costs can appear as direct costs and include activities such as monitoring, data gathering, analysis and evaluation of direct manipulations. Other costs can be viewed as opportunity costs; the cost of using a resource for manipulation rather than for another use. One such example is the cost of experimental water releases from the Glen Canyon, but the situation is very similar in the Missouri and Platte Rivers. Although water releases from the Glen Canyon dam are required under the Colorado Compact, water can be released through the turbines that generate electrical energy or water can be released through by-pass tubes. Water released for experimental purposes through the by-pass tubes does not generate electrical revenue (or, in the other examples, is not available for barge traffic, or the irrigation of crops). Some estimates have been made of lost revenues on the order of hundreds of thousands of dollars. In other words, this is an example where the opportunity costs can be reasonably estimated, and is high. One suggestion as to why a long term (multiple decades) experimental plan could not be agreed upon for the Glen Canyon adaptive management program was the proposed cost of evaluation.

\subsection{Surprises are suppressed}

Surprises are expected in complex social-ecological systems, perhaps especially when we attempt to anticipate them. Surprise may come in the form of natural disaster (drought, hurricane), or as a departure from anticipated human behaviors, or from other sources. When surprises intervene in adaptive management 
programs, they should be embraced as opportunities to learn rather than as externalities. Humans are poor at dealing with uncertainty and surprise. Human response to an uncertain future driven by anthropogenic stress is to attempt to anticipate that surprise, and 'mitigate' it. Of course if surprise can be anticipated it is unlikely to be surprising.

A focus of the Platte River Recovery Adaptive Management Program (Smith, 2010) is to restore sandbar habitat for endangered interior least terns (Sterna antillarum athalassos) and piping plovers (Charadrius melodus). The potential management actions that might meet the goal of habitat restoration include mechanical movement of sand with heavy machinery and surge flows originating from releases from a reservoir upstream. Both management actions are made more difficult due to the colonization of sandbars by cottonwoods and other woody vegetation, which must be removed before other management can occur. In the Platte River, the historic structuring process was flooding. Even if the historic hydrologic regime could be restored, the river would not respond as before, because woody vegetation has armored the sandbars, so that flooding is not likely to mobilize the islands. Thus, simply restoring the former structuring process will not restore structure, and woody vegetation has to be removed before flooding (surges) can have an impact on habitat. This is an example of hysteresis, "when the path in is different from the path out". The Platte River Recovery Program (and other stakeholders such as the Fish and Wildlife Service and Nature Conservancy) understands this, and as a result, are working to mechanically remove trees.

By the year 2000, an invasive wetland plant, the common reed (Phragmites australis), had become established along the Platte River, further entrenching the hysteresis caused by vegetative stabilization of sandbars. This was a surprise in that it was unanticipated, and that common reed's invasion of shallow water and moist habitats was nearly complete and extremely rapid. Flows of the Platte were slowed, creating flooding and further altering the river's hydrology. Management of common reed was not included in the Platte River Recovery Management Plan, and its rapid spread throughout the river system created challenges. One of the initial responses discussed by the Platte River Program Governance Committee was to treat invasion by common reed as external, and attempt to eradicate it and then continue with the planned adaptive management. Luckily, this did not happen and management of this invasive species is being incorporated into the Platte River Program adaptive management plan. However, that initial response did receive serious consideration, and similar responses have occurred elsewhere.

\subsection{Prescriptions are followed}

Adaptive management is prescriptive only in process, though formally identifying objectives and alternative actions giving support for one alternative or another is critical. However, if management is seeking to optimize learning, then it is not possible to anticipate every bifurcation possible following individual experiments. Surprises, for example, as described above, are opportunities for more than the usual amount of learning (and thus "better" management). But the unanticipated can be less startling than surprises, as more and more is learned about the system under management, new information informs new management. This new information can be noted and put away, and managers can proceed with the adaptive management plan originally formulated, or the plan can be reformulated. Adaptive management processes that are too complex in their internal organization and too complex and fragile in their stakeholder network are apt to stick to the prescription no matter what. After all, it can take years of process to reach management agreements.
Although it is difficult to admit a lack of prescience, a good adaptive management plan is likely to eventually make the adaptive management plan obsolete. This is actually a good thing, and indicates that management has generated new knowledge. That knowledge should be embraced, and adaptive management plans should be revisited, dropped, and rewritten as a matter of course.

\subsection{Action procrastination: learning and discussion remain the only ingredients}

Process should not trump action, and the implementation of what has been learned. Management is central in adaptive management, but can be halted by calls for 'more science', which often represents a stalling tactic. Many complex and difficult environmental challenges have been left unaddressed for years by hiding behind the need for more science. Although no action is in fact a management action, in this case we are referring to situations where action is desired but prevented by obstructionists to the process. Such obstruction is often political in nature. Often, this action procrastination leads to missed opportunities and more intractable problems in the near future. Examples include climate change and the management of salmon stocks in the western United States. Lee (1993) provides additional examples.

\subsection{Learning is not used to modify policy and management}

Adaptive management can be used by politicians as a method to placate stakeholders while continuing business as usual. This runs counter to the basic tenets of adaptive management, whereby management can proceed despite uncertainty as long as management actions are designed to reduce that uncertainty over time. This pathology is similar to the one described above, but here what is learned is critical and important, but is shelved because the management actions identified and necessary are too politically, economically, or logistically difficult. Salmon management in the Pacific Northwest is once again an example, where the management objective is to conserve distinct stocks of salmons, and viable populations of those stocks. Removal of dams would clearly benefit salmon stocks, and indeed, for salmon runs blocked by dams, other actions which may further aid salmon stocks may be trivial by comparison.

\subsection{Avoiding hard truths: decision makers are risk averse}

It is possible to conduct small management experiments into perpetuity while never tackling the critical but controversial underlying management challenges. Here, the necessary management is not known with surety, but it is likely that it is logistically and politically difficult and expensive; or, the outcome is anticipated to be economically or politically expensive. To avoid hard truths small-scale management experiments are conducted, which may improve management and the state of the resource, around the edges. Many large river adaptive management programs fall into this category, and may focus on manipulations to improve habitat rather than restoring processes - usually flooding and hydrological variation.

Endangered species management can too fall into this trap. In the management of critically endangered species, both risk (the probability of a "bad" result) and uncertainty can be high (Fig. 2). Where the risk is simply too great, adaptive management may not be the strategy to employ, and managers should use other approaches, though risk can be accounted for in decision making. The California condor (Gymnogyps californianus), when the wild population was reduced to a handful of individuals, was not a good 


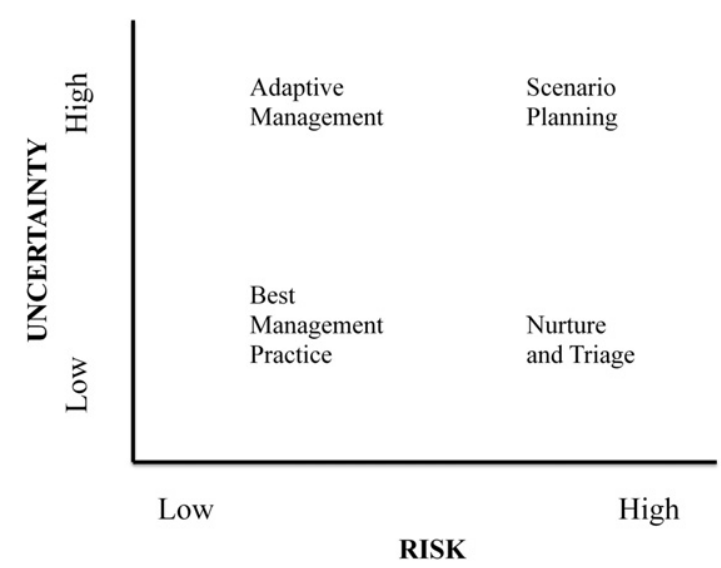

Fig. 2. Adaptive management is appropriate where the level of risk is relatively low, where it is "safe" to conduct experiments.

candidate for adaptive management. For one, critical experiments were too risky (such as attempting to establish a second population); additionally, critically endangered species are unlikely to yield enough data in terms of sample size to actually assess the success of management experiments. Ultimately, for this species, the lowest risk path, removal of the population from the wild and captive breeding, was taken. In cases such as this, a cautious application of structured decision making can yield positive results for the resource at stake (e.g., Rout et al., 2009; Tenhumberg et al., 2004).

\subsection{The process lacks leadership and direction}

Stakeholders should not be decision makers, and no stakeholder group should have more influence than others. Strong, but beneficent, leadership is critical, as is the ability to facilitate; facilitator and leader can be separate roles. Too often a very vocal or influential individual, or stakeholder group, hijacks the process. This can lead to a process to address a specific agenda other than learning how to best manage. The adept leader of an adaptive management effort should recognize the personalities involved and make the best of all of them (Holling and Chambers, 1973), and should recognize both blatant and hidden agendas. Appeasing vociferous stakeholders will simply alienate the remaining stakeholders and undermine the adaptive management process.

\subsection{Focus on planning, not action}

Large adaptive management programs can become stuck in a planning loop. This can be due to a desire for perfection and success, the mistaken belief that the adaptive management plan is a panacea rather than a process and must be perfect, or because the funding or sponsoring agency wishes to keep the process in an endless planning loop. Either is a serious pathology that must be recognized and rectified. In some large adaptive management programs, programmatic compartmentalization within bureaucracies may mean that there is plenty of funding available to establish the process, or for monitoring, but not for experiments.

\section{Summary}

The conceptual underpinnings for adaptive management are quite simple; there will always be inherent uncertainty in the dynamics and behavior of complex ecologic systems. As a result of the numeric complexity and non-linear interactions among components, there will always be inherent unpredictability. The genius of adaptive management lies in the continuing recognition and confrontation of such uncertainty. Rather than assume uncertainty away or use it to preclude management actions, adaptive management can help foster resilience and flexibility to deal with an uncertain future, and develop safe to fail designs that acknowledge inevitable change and surprise.

The central argument of adaptive management is integrative learning. That learning is fostered, not by trial and error, but by a structured process, and reduces uncertainty in an iterative process. This integrative learning is described in phases of assessment, policy as hypotheses, management actions as tests, and evaluation. Assessment phases of adaptive management involve bounding issues, focusing on shared understanding of policy relevant hypotheses and screening alternatives for testing. In some resource assessments, a singular hypothesis can be generally agreed upon for testing via management actions. In many cases, multiple, competing hypotheses can be generated and spawn a suite of activities; research, modeling, data collection and adaptive management actions can all help sort among these competing ideas.

The experiences of applying active adaptive management however, have had mixed success. Adaptive assessments have robustly transformed understanding and generated totally new management schemes in many areas, such as in the Everglades (Gunderson and Light, 2006) Grand Canyon (Walters, 1997). Active adaptive management (designed to test or sort among competing hypotheses) has failed in most large-scale applications. Successful adaptive management, defined as the ability to plan, execute and evaluate experiments which in turn, lead to new or revised management policies have occurred in a few select programs, such as the Grand Canyon (Zellmer and Gunderson, 2009). Programmatic failures have been a result of a lack of ecological resilience, inability to control experimentation at appropriate scales, and the lack of flexibility, trust and openness in the human management system (Gunderson and Light, 2006).

The potential pitfalls in adaptive management, and the pathologies that can develop, have some commonalities. For one, the process can be hijacked by those with specific agendas. The agenda can be one associated with the specific management issue at hand, or may simply represent bureaucratic pathology whereby the adaptive management process is invoked to delay the process of making hard decisions. There are some signs that can indicate the process is failing, some glaringly obvious, some more subtle. On the obvious front, making stakeholders cry by badgering them during the process (witnessed by one of the authors) is a telltale sign of process gone awry. If stakeholders all have a different definition of adaptive management, there may be a problem. If stakeholders claim they've been doing this all along, there is probably a problem. If the managed resource continues to degrade while the process is stuck in a discussion loop, there is a problem. If no experimental management is occurring, there is no adaptive management.

Adaptive assessment and management confronts the inherent uncertainty of resource management systems and in doing so intersects with the themes of this issue of the Journal of Environmental Management. Scale should be explicitly defined, which may be accomplished by developing an integrated ecosystem model. The model is bounded in both spatial and temporal domains, and can only minimally deal with larger, slower processes and smaller, faster processes. This scale bounding is one source of uncertainty in the assessment process. In the management phase, limits in space and time are imposed by the ability of managers to act within a system. Social networks that are 
centered on epistemic communities and extend to stakeholder and policy groups are developed in adaptive assessments and are critical to successes and failures of implementation and management (Gunderson, 1999). In spite of limitations, adaptive management is a robust approach for dealing with complex natural resource issues; from renewable resource harvest and use, to pure conservation. Its focus on learning, integrating understanding and generation of novelty are as relevant now as decades ago when it was developed. The adaptive management approach can bridge gaps in understanding and create new and novel approaches. Recognition of barriers will foster that development and the application of a conceptually robust approach to solving old problems.

\section{Conclusions}

Adaptive management is perhaps too often seen as the only way forward for wicked social-ecological problems, such as presented by the management of stressed and over-appropriated watersheds that transcend multiple jurisdictions (e.g., the Everglades, the Colorado River, the Missouri River). These are not the ideal situations for the application of adaptive management, because replication is not possible and experiments are highly constrained by entrenched management, engineering, economic and social systems. In such situation, adaptive management can be seen as the action of last resort, and used to maintain the status quo. We envision the most appropriate use for adaptive management is not for such intractable social problems, but is rather most appropriate and useful where a great deal of scientific uncertainty exists, sufficient resources allow for experimentation with multiple treatments, competing hypotheses are present but finite and testable, and leadership that can overcome vested and self serving stakeholders who are adept at preventing active experimentation.

\section{Acknowledgements}

The Nebraska Cooperative Fish and Wildlife Research Unit is jointly supported by a cooperative agreement between the United States Geological Survey, the Nebraska Game and Parks Commission, the University of Nebraska-Lincoln, the United States Fish and Wildlife Service and the Wildlife Management Institute. Reference to trade names does not imply endorsement by the authors or U.S. government.

\section{References}

Allan, C., Curtis, A., 2005. Nipped in the bud: why regional scale adaptive management is not blooming. Environmental Management 36, 414-425.

Baron, J., Gunderson, L., Allen, C.D., Fleishman, E., McKenzie, D.H., Meyerson, L.A., Oropeza, J., Stephenson, N., 2009. Adapting to climate change: options for national parks and reserves. Environmental Management 44, 1033-1042.

Feldman, D.L., 2008. Barriers to adaptive management: lessons from the Apalachicola-Chattahoochee-Flint compact. Society and Natural Resources 21, 512-525.

Gregory, R., Ohlson, D., Arvai, J., 2006. Deconstructing adaptive management: criteria for applications to environmental management. Ecological Applications $16,2411-2425$

Gunderson, L., 1999. Resilience, flexibility and adaptive management - antidotes for spurious certitude? Conservation Ecology 3 (1), 7. [online] URL: http://www. consecol.org/vol3/iss1/art7/.

Gunderson, L.H., Holling, C.S., Light, S., 1995. Barriers and Bridges to Renewal of Ecosystems and Institutions. Columbia University Press, New York, NY, USA.

Gunderson, L.H., Light, S.S., 2006. Adaptive management and adaptive governance in the Everglades. Policy Sciences 39, 323-334.

Holling, C.S. (Ed.), 1978. Adaptive Environmental Assessment and Management John Wiley, New York, New York, USA.

Holling, C.S., Chambers, A.D., 1973. Resource science: the nurture of an infant BioScience 23, 13-20.

Holling, C.S., Meffe, G.K., 1996. On command-and-control, and the pathology of natural resource management. Conservation Biology 10, 328-337.

Lee, K.N., 1993. Compass and Gyroscope-Integrating Science and Politics for the Environment. Island Press, Washington DC.

Lee, K.N., 1999. Appraising adaptive management. Conservation Ecology 3 (2), 3. [online] URL: http://www.consecol.org/vol3/iss2/art3/.

Ludwig, D., 2001. The era of management is over. Ecosystems 4, 758-764.

Moir, W.H., Block, W.M., 2001. Adaptive management on public lands in the United States: commitment or rhetoric? Environmental Management 28, 141-148.

Peterson, G.D., Cumming, G.S., Carpenter, S.R., 2003. Scenario planning: a tool for conservation in an uncertain world. Conservation Biology 17, 358-366.

Rittel, H.W.J., Webber, M.M., 1973. Dilemmas in a general theory of planning. Policy Sciences 4, 155-173.

Rout, T.M., Hauser, C.E., Possingham, H.P., 2009. Optimal adaptive management for the translocation of a threatened species. Ecological Applications 19, 515-526.

Smith, C., 2010. (This issue of JEM - to be added).

Susskind, L., Camacho, A.E., Schenk, T., 2010. Collaborative planning and adaptive management in Glen Canyon: a cautionary tale. Columbia Journal of Environmental Law 35, 1-54.

Tenhumberg, B., Tyre, A.J., Shea, K., Possingham, H.P., 2004. Linking wild and captive populations to maximize species persistence: optimal translocation strategies. Conservation Biology 18, 1304-1314.

Walters, C.J., 1986. Adaptive Management of Renewable Resources. McMillan, New York, New York, USA.

Walters, C.J., 1997. Challenges in adaptive management of riparian and coastal ecosystems. Conservation Ecology 1 (2), 1. [online] Available from the Internet. URL: http://www.consecol.org/vol1/iss2/art1/.

Walters, C.J., 2007. Is adaptive management helping to solve fisheries problems? Ambio 36, 304-307.

Williams, B.K., Szaro, R.C., Shapiro, C.D., 2009. Adaptive Management: The U.S Department of the Interior Technical Guide. Adaptive Management Working Group, U.S. Department of the Interior, Washington, DC.

Zellmer, S., Gunderson, L., 2009. Why resilience may not always be a good thing: lessons in ecosystem restoration from Glen Canyon and the Everglades. Nebraska Law Review College of Law, University of Nebraska, Lincoln. 